\title{
Communications
}

\section{Prophylaxis of retinal detachment}

\author{
A. H. GHIGNELL AND J. SHILLING \\ Moorfields Eye Hospital, City Road, London, E.C.I.
}

The detection of conditions which may lead to retinal detachment is of great importance to the ophthalmologist. Opinions vary, however, as to which lesions should be treated, as the dangers and practicability of treatment have to be balanced against the need to prevent retinal detachment whenever possible. The two main conditions for consideration are those of retinal holes and lattice degeneration.

\section{RETINAL HOLES}

The well-known risk of untreated retinal holes was stressed by Meyer-Schwickerath (1964) who reported a 28 per cent. risk of detachment in a group of patients with untreated retinal holes, and by Lincoff ( $196 \mathrm{I}$ ) who pointed out the relative dangers of different types of retinal holes, large horseshoe-shaped tears being more dangerous than round holes. However, Rutnin and Schepens ( 1967 ), emphasizing the need for indirect ophthalmoscopy combined with scleral depression, reported retinal breaks in 7.8 per cent. of normal eyes examined, and Okun ( $196 \mathrm{I}$ ), in a study of autopsy eyes, found an incidence of unsuspected retinal holes in $4^{\cdot 8}$ per cent. In support of those findings, Cockerham and Freeman (1968) and Byer (1967) urged conservatism in the treatment of very small flat peripheral retinal holes. Neumann and Hyams (1972), in a review of retinal holes treated conservatively, felt that fresh tears were more likely to lead to detachment than old ones.

It is still not possible to forecast with certainty which retinal hole will proceed to retinal detachment.

\section{LATTICE DEGENERATION}

The high incidence of lattice-like degeneration noted at autopsy by Straatsma and Allen ( 1962 ) and clinically by Byer ( 1965 ) in normal eyes, renders it impractical and unnecessary to treat all patients with these appearances. However, true lattice degeneration is a known precursor of retinal detachment and, in a review of Ioo eyes with retinal detachment, Dumas and Schepens ( 1966) found lattice degeneration in thirty of them. Many authors feel that treatment of lattice degeneration is indicated when retinal holes have formed in the degenerate area (Lincoff, I96 I ; Zweng, Little, and Peabody, I969), but the indications for the treatment of lattice degeneration when holes are not present are less clear.

The purpose of this paper is to report the results of prophylactic treatment carried out in this unit over the last few years. The data on 202 patients are considered and the main clinical details discussed. 


\section{Material}

202 patients (23I eyes) admitted between 1966 and 1970 for prophylactic treatment were studied, and were treated on the following basis:

RETINAL HOLES

All flat retinal holes were treated, with the exception of macular holes and in some cases of very small round holes just posterior to the ora serrata.

LATTICE DEGENERATION

This was treated in the following circumstances (after Blach and Bedford, I966):

(a) The presence of retinal holes.

(b) Retinal detachment in the same or the other eye.

(c) A family history of detachment.

In this study the term lattice degeneration has been used only when the true white lines as described by Vogt (1924) were present.

The follow-up period varied from 4 years to a minimum of 1 year from the date of the last treatment.

\section{Findings}

Of the 202 patients treated, men outnumbered women by 120 to 82 . The 40 to 60 -year age group was favoured (49 per cent.) and the right eye was affected more than the left (Table I).

Table I Prophylaxis on 202 patients

\begin{tabular}{|c|c|c|c|c|c|c|c|}
\hline \multicolumn{2}{|l|}{ Sex } & \multicolumn{3}{|c|}{ Age group (yrs) } & \multicolumn{3}{|l|}{ Eye affected } \\
\hline Male & Female & $0-40$ & $40-60$ & $6 o+$ & Right & Left & Both \\
\hline $120(59 \%)$ & $82(41 \%)$ & $4 \mathrm{I}(20 \%)$ & $99(49 \%)$ & $62(31 \%)$ & $96(48 \%)$ & $77(38 \%)$ & $29(14 \%)$ \\
\hline
\end{tabular}

Refractive error

The refractive error of the $23^{1}$ eyes is summarized in Table II; 128 eyes (55 per cent.) were found to be myopic.

Table II To show the refractive error of the $23 \mathrm{I}$ eyes treated

\begin{tabular}{|c|c|c|c|c|}
\hline \multicolumn{3}{|l|}{ Myopia $(D)$} & \multirow{2}{*}{ Aphakia } & \multirow{2}{*}{$\begin{array}{l}\text { Emmetropia } \\
\text { or } \\
\text { hypermetropia }\end{array}$} \\
\hline $7-10$ & -5 to -10 & o to -5 & & \\
\hline $20(8.8 \%)$ & $37(15.5 \%)$ & $5(28 \%)$ & $7(3 \%)$ & $102(45 \%)$ \\
\hline
\end{tabular}

Indications for treatment (Table III)

Retinal holes, either alone or in combination with lattice degeneration, form the biggest group, accounting for 170 (73 per cent.) of the eyes treated. Of the 48 eyes receiving prophylaxis for lattice degeneration (Table IV), 42 had had a detachment procedure to the other eye. There were thirteen cases in which the retina was treated, but it was not possible accurately to classify the appearance and these were classed as "weak" areas of retina. 
Table III Indications for treatment in $23 \mathrm{I}$ eyes

Table IV Reasons for treatment of 48 cases of lattice degeneration without holes

\begin{tabular}{lrrr} 
& \multicolumn{2}{c}{ Cases } \\
\cline { 3 - 4 } Conditions & & No. & Per cent. \\
\cline { 4 - 4 } Retinal holes alone & & 106 & 46 \\
Lattice degeneration + holes & & 64 & 27 \\
Lattice degeneration alone & & $4^{8}$ & 21 \\
"Weak" areas of retina & & 13 & 6 \\
\hline
\end{tabular}

\begin{tabular}{lcc}
\hline Reason & No. of eyes \\
\cline { 1 - 1 } $\begin{array}{lc}\text { Other eye had detachment } \\
\text { Bilateral high myopia under age }\end{array}$ & 42 \\
$\begin{array}{lc}\text { Extensive bilateral lattice in } \\
\text { young emmetrope }\end{array}$ & 5 \\
\hline Total & I \\
\hline
\end{tabular}

\section{Method of treatment}

Cryotherapy and photocoagulation were used (Table V). The use of cryotherapy is being increasingly favoured when the trend of treatment over the 4 years is considered. The ratio was $I: I$ in $1967-8$ and $3: 1$ in $1969-70$.

Table $\mathbf{V}$ Method of treatment in 231 eyes

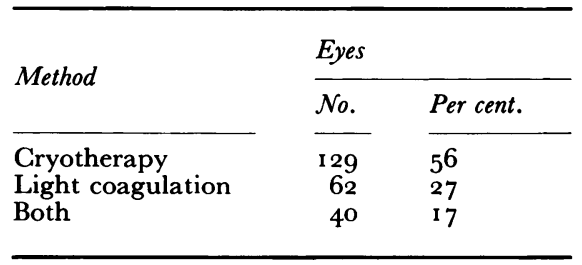

\section{Treatment}

In most eyes (69 per cent.) only one treatment was required, and in 65 per cent. only one quadrant of the retina needed treatment (Tables VI and VII).

Table VI Number of treatments required in $23^{1}$ eyes

\begin{tabular}{|c|c|c|c|c|c|}
\hline \multirow{2}{*}{ Eyes } & \multicolumn{5}{|c|}{ No. of treatments required } \\
\hline & I & 2 & 3 & 4 & Total \\
\hline No. & 159 & $5^{8}$ & II & 3 & 320 \\
\hline Per cent. & 69 & 26 & 4 & I & IOO \\
\hline
\end{tabular}

Table VII Extent of treatment in $23 \mathrm{I}$ eyes

\begin{tabular}{|c|c|c|}
\hline \multirow{2}{*}{ Quadrants } & \multicolumn{2}{|c|}{ Eyes } \\
\hline & No. & Per cent. \\
\hline Less than I & 152 & 65 \\
\hline $1-2$ & 49 & 21 \\
\hline $2-3$ & I5 & 7 \\
\hline $3-4$ & I 5 & 7 \\
\hline
\end{tabular}

The total number of treatments was 320 . When the distribution of applications was considered, it was seen that at the first treatment the upper temporal quadrant is most often affected ( 34 per cent.) but that this is not the case with subsequent treatments (Table VIII). The upper half of the retina was more often treated than the lower half.

Examination of the other eye

In 136 patients $(66.5$ per cent.) a retinal detachment procedure had been undertaken in 
Table VIII Distribution of prophylactic treatment

\begin{tabular}{|c|c|c|c|c|c|c|c|c|c|c|c|c|}
\hline \multirow{4}{*}{ Treatment } & \multicolumn{8}{|c|}{ Quadrant treated } & \multicolumn{4}{|c|}{ Half of retina treated } \\
\hline & \multicolumn{4}{|c|}{ Temporal } & \multicolumn{4}{|c|}{ Nasal } & \multirow{2}{*}{\multicolumn{2}{|c|}{ Upper }} & \multirow{2}{*}{\multicolumn{2}{|c|}{ Lower }} \\
\hline & \multicolumn{2}{|l|}{ Upper } & \multicolumn{2}{|c|}{ Lower } & \multicolumn{2}{|c|}{ Upper } & \multicolumn{2}{|c|}{ Lower } & & & & \\
\hline & No. & $\begin{array}{l}\text { Per } \\
\text { cent. }\end{array}$ & $\mathcal{N} o$ & $\begin{array}{l}\text { Per } \\
\text { cent. }\end{array}$ & $\mathcal{N} o$ & $\begin{array}{l}\text { Per } \\
\text { cent. }\end{array}$ & $\mathcal{N} o$ & $\begin{array}{l}\text { Per } \\
\text { cent. }\end{array}$ & No. & $\begin{array}{l}\text { Per } \\
\text { cent. }\end{array}$ & No. & $\begin{array}{l}\text { Per } \\
\text { cent. }\end{array}$ \\
\hline First & I 55 & 34 & I I 9 & 26 & 112 & 25 & 70 & 15 & 267 & 59 & I 89 & $4^{1}$ \\
\hline Second & 37 & $3^{\mathbf{I}}$ & 33 & 28 & 29 & 24 & 20 & I 7 & 66 & 55 & 53 & 45 \\
\hline More than two & 6 & 20 & 9 & $3^{I}$ & 5 & 18 & 9 & 31 & I I & 38 & I 8 & 62 \\
\hline
\end{tabular}

the other eye (Table IX). Bilateral prophylaxis was carried out in 24 patients and in only 34 patients ( 77 per cent.) was the other eye considered to be normal.

Table IX State of other eye in 202 cases treated prophylactically

\begin{tabular}{|c|c|c|}
\hline Diagnosis of other eye & No. & Per cent. \\
\hline $\begin{array}{l}\text { Detachment successfully treated } \\
\text { unsuccessfully treated }\end{array}$ & $\begin{array}{l}83 \\
53\end{array}$ & $\begin{array}{l}41 \cdot 5 \\
26\end{array}$ \\
\hline Normal & 34 & I 7 \\
\hline Also received prophylaxis & 29 & 14 \\
\hline Marked retinoschisis & 2 & I \\
\hline Total vitreous haemorrhage & I & 0.5 \\
\hline
\end{tabular}

Anaesthesia

Of the 320 treatments, bilateral prophylaxis was performed in 24 patients, leaving a total of 296 separate procedures. General anaesthesia was used in 160 ( 56 per cent.) and local anaesthesia in the rest ( 46 per cent.).

An analysis of the former shows that in only 72 cases (23 per cent. of the 296 procedures) was general anaesthesia given for unilateral prophylaxis.

\section{Visual acuity}

The visual acuity of the treated eyes was assessed at least one year from the time of the last treatment. Cases were deemed to be worse if the acuity had fallen by more than one line as measured on the Snellen test chart, and this was so in only nine cases (4 per cent.). Subsequent retinal detachment with involvement of the macula was the cause in five cases but in two cases macular pucker occurred. One case of macular pucker appeared to be precipitated by cryotherapy, the other by photocoagulation. In the first a retinal hole in the upper temporal quadrant had been treated and in the second the hole was in the lower temporal quadrant. In both patients, vision became affected approximately 6 weeks after treatment, with irreversible reduction of central vision. Reduction of visual acuity in the two remaining patients was caused by lens opacities in one case and cranial arteritis in the other. 


\section{Retinal detachment}

This has so far occurred in twelve eyes after prophylaxis ( 5 per cent.). Detachment after prophylaxis with photo-coagulation has also been reported by Ten Doesschate ( 1965 ), who found an incidence of 14 per cent. and by Colyear (1965), who found an incidence of $4 \cdot I$ per cent. Details of the detachments occurring in the present study are recorded in Table X. Ten patients were treated with cryosurgery and two with photocoagulation (Cases 5 and 8). All received prophylaxis for retinal holes, except Case 5, in which treatment was given before cataract extraction in an attempt to obviate the risk of subsequent aphakic detachment, and Case I, which was treated for lattice degeneration only. In Cases 1 to 5 detachment was associated with retinal holes at a site other that that previously treated. Case 3, which had originally suffered extensive vitreous haemorrhage, progressed rapidly to massive vitreous retraction.

Table $\mathbf{X}$ Details of twelve detachments which occurred after prophylaxis

\begin{tabular}{|c|c|c|}
\hline Case no. & $\begin{array}{l}\text { Length of time after } \\
\text { prophylaxis }\end{array}$ & From place other than treated site \\
\hline $\mathbf{I}$ & 2 wks & Yes \\
\hline 2 & 2 mths & Yes \\
\hline 3 & 2 mths & Yes (vitreous haemorrhage) \\
\hline 4 & $4 \mathrm{mths}$ & Yes \\
\hline 5 & $\begin{array}{l}6 / 12 \text { after extraction. } \\
\text { I year after treatment }\end{array}$ & Yes \\
\hline 6 & Immediate & No (vitreous haemorrhage) \\
\hline 7 & Immediate & No (preoperative subretinal fluid) \\
\hline 8 & Immediate & No (preoperative subretinal fluid) \\
\hline 9 & I wk & No (hole near edge of cryosurgery) \\
\hline Io & 2 mths & No (preoperative subretinal fluid) \\
\hline I I & 2 mths & No (hole near edge of cryosurgery) \\
\hline 12 & 2 mths & No (hole from posterior edge of cryosurgery) \\
\hline
\end{tabular}

In cases 6 to 12, detachment was related to the site of prophylaxis. In three (Cases 7 , 8 , and 10), preoperative subretinal fluid was present and an attempt was made to secure the retina without a scleral buckle. There was rapid accumulation of subretinal fluid in the postoperative period, which necessitated further surgery. Case 6, in which there was a marked preoperative vitreous haemorrhage, developed a detachment after treatment to a retinal hole. Cases 9 and i I developed detachment from holes immediately adjacent to the treated areas, but it was impossible to tell whether these holes were fresh tears or had been previously observed. In Case 12 a U-shaped tear developed from the posterior margin of the treated retina 2 months after treatment with cryotherapy.

\section{Discussion}

Retinal holes, either alone or in combination with lattice degeneration, form by far the largest group (73 per cent.) to receive prophylactic treatment. This reflects the view that these cases are most likely to develop retinal detachment; this is supported by Merin, 
Feiler, Hyams, Ivry, Krakowski, Landau, Maythar, Michaelson, Scharf, Schul, and Ser ( 197 I) who, in strongly advocating prophylaxis, found that retinal detachment afterwards developed in nearly 20 per cent. of fellow eyes with untreated retinal holes.

Lattice degeneration, when holes are not present, is treated only in specific high-risk situations when retinal detachment seems likely to occur. Thus it was seen that the majority of patients with lattice degeneration only who received treatment were those in whom a retinal detachment had occurred in the other eye $\left(4^{2}\right.$ patients). Six other cases in this group, who were felt to represent bad retinal risks, were also treated, and these were all young patients, five with a high degree of myopia. It may be that vitreous traction at the site of lattice degeneration should be one of the decisive factors in deciding whether to treat or not, the presence of marked vitreous adhesion favouring treatment.

There is an increasing tendency to use cryotherapy, and this technique is of particular value in the treatment of peripheral retinal disease. In most cases transconjunctival applications of cryotherapy are used and it is necessary to incise the conjunctiva only when the lesions to be treated are posterior to the equator.

Only one treatment has been required so far in the majority of cases (69 per cent.), but it is possible that further treatments may be necessary in the future. The upper temporal quadrant was most frequently affected (34 per cent.), supporting the findings of Dumas and Schepens (I 966), and, as expected, after the first treatment other quadrants were treated with increasing frequency. A failed or successful retinal procedure had often been carried out in the fellow eye in the patients studied $(66.5$ per cent.); this high percentage stresses the need for sustained and intensive vigilance in watching the second eye of a retinal detachment patient. It is now our practice to perform careful indirect ophthalmoscopy with scleral depression of the fellow eye at the time of surgery in all patients undergoing retinal operations. The great ease with which this may be done under general anacsthesia may reveal hitherto undetected retinal breaks, particularly in patients on whom preoperative scleral depression is difficult.

General anaesthesia was necessary in only a minority of patients (23 per cent.) who received prophylaxis to one eye and were not undergoing simultaneous retinal surgery to the other eye. Repeated treatment is often necessary in patients with retinal disease, and general anaesthesia for prophylaxis should be avoided when possible. We have found premedication followed by retrobulbar anaesthesia to be satisfactory in all but the most difficult cases.

In two cases macular pucker occurred after treatment, in one after cryotherapy and in the other after photocoagulation. Both cases were uncomplicated and required treatment for retinal holes and there was no pre- or postoperative vitreous haemorrhage. The occurrence of macular pucker after various forms of retinal surgery has been described by Tanenbaum, Schepens, Elzeneiny, and Freeman (1970). In both our cases, vision fell irreversibly to $6 / 60$. The occurrence of this serious complication is so far quite unpredictable and, although it is a rare complication, its occasional appearance urges conservatism in patients in whom the need for prophylactic treatment is doubtful.

Of the retinal detachments occurring after prophylaxis from a site other than the treated area, Cases I, 2, and 4 were caused either by fresh tears or by tears that had previously been undetected. In Case 3, parts of the retina had been obscured by vitreous haemorrhage, so that a second tear was undetected and the treatment appeared to precipitate immediate detachment of the retina; in this case the vitreous haemorrhage may also have obscured the presence of subretinal fluid. Massive vitreous retraction rapidly followed. In Case 5, detachment occurred behind a previous encircling barrage of photocoagulation. 
Of Cases 6 to 12, in which detachment occurred from the immediate vicinity of the treated area, three (Cases 7, 8, and 10) had preoperative subretinal fluid and in a fourth case, in which vitreous haemorrhage prevented adequate examination, subretinal fluid may have been present. In all these cases there was rapid accumulation of subretinal fluid in the postoperative period and this was particularly noticeable in the two cases treated with cryotherapy. It is now our practice never to treat any tear associated with subretinal fluid with a prophylactic procedure alone; a buckling procedure is routinely performed. Vitreous haemorrhage in Case 6 resulted in inaccurate placement of the prophylactic therapy. In Cases 9 and I I, detachment occurred from small holes very near the treated area, but it was not possible to be certain if these holes had arisen de novo. In Case 9, when detachment occurred 2 weeks after treatment, prophylaxis may have promoted the occurrence of the retinal detachment. In Case 12, a U-shaped tear, which appeared on the posterior edge of a previous area treated with cryotherapy, resulted in retinal detachment 2 months after the original prophylaxis.

\section{Summary}

A survey of prophylactic treatment has been made and the data on 202 selected patients (231 eyes) treated between 1967 and 1970 examined. We have used cryotherapy with increasing frequency, and local anaesthesia was preferred whenever possible. The main indications for treatment were retinal holes (73 per cent.) and lattice degeneration without holes ( 2 I per cent.), treatment of the latter being particularly important when detachment has occurred in the other eye. In the initial treatment, the upper temporal quadrant is most often affected ( 65 per cent.), and so far only one treatment has usually been necessary (69 per cent.). Visual acuity fell markedly in nine cases (4 per cent.) after treatment, and in two cases this was caused by macular pucker. This disastrous complication is unpredictable in its occurrence and should serve as a restraint against unnecessary prophylaxis. Prophylaxis alone should not be undertaken in the presence of subretinal fluid, as treatment with cryotherapy may further increase the formation of fluid and produce more marked retinal detachment.

The other eye was considered normal in only 17 per cent. of cases, and detachments had occurred in 65.5 per cent. of fellow eyes; the importance of sustained vigilance and treatment, when necessary, of the fellow eye in a patient with a retinal detachment, is particularly stressed. As yet, it is impossible to know for certain which cases with flat retinal holes, with or without lattice degeneration, will proceed to detachment. Thus, although the occurrence of retinal detachment after prophylaxis is so far only 5 per cent. in this series, it is felt that the incidence of detachment in the high-risk group of patients studied would have been far higher if treatment had not been given.

Our thanks are due to Mr. L. G. Fison for permission to study his cases and to Miss S. Anderson and Miss S. Heeps for invaluable secretarial assistance. This work was in part supported by the Clothworkers' Company.

\section{References}

BLACH, R. K., and BEDFORD, M. A. (1966) Trans. ophthal. Soc. U.K., 86, 463

BYER, N. E. (1965) Trans. Amer. Acad. Ophthal. Otolaryng., 69, I064 ( 1967$)$ Ibid., 71, $46 \mathrm{I}$

COCKERHAM, W. D., and FREEMAN, H. M. (1968) Arch. Ophthal. (Chicago), 79, 655

colyear, B. H. (1965) Trans. Amer. Acad. Ophthal. Otolaryng., 69, 879 
dumas, J., and schepens, c. L. (1966) Amer. J. Ophthal., 6r, 620 LINCOFF, H. A. (I96I) Arch. Ophthal. (Chicago), 66, 48.

MERIN, S., FEILER, V., HYAMS, S., IVRY, M., KRAKOWSKI, D., LANDAU, L., MAYTHAR, B., MichAELSON, I. C., SCHARF, J., SGHUL, A., and SER, I. (I97I) Amer. J. Ophthal., 71, 477

MEYER-SChWICKERATH, G. (1964) Trans. Canad. ophthal. Soc., 1963, 26, 9

NEUMANN, E., and HYAMS, s. (I972) Brit. F. Ophthal., 56, 482

okun, E. (1961) Amer. J. Ophthal., 51, 369

RUTNIN, U., and SCHEPENS, c. L. (1967) Ibid., 64, 1063

straftsma, B. R., and Allen, R. A. (ig62) Trans. Amer. Acad. Ophthal. Otolaryng., 66, 600 TANENBAum, H. L., Schepens, G. L., elzeneiny, I., and freeman, H. м. (1970) Arch. Ophthal. (Chicago), 83, 286

TEn doesschate, J. (1965) Trans. Amer. Acad. Ophthal. Otolaryng., 69, 869 vogt, A. (1924) Klin. Mbl. Augenheilk., 72, 212

zWeng, H. G., Little, H. L., and PEABOdy, R. R. (I969) "Laser Photocoagulation and Retinal Angiography". Mosby, St. Louis 